\section{International Scientific Journal Theoretical \& Applied Science}

p-ISSN: 2308-4944 (print) e-ISSN: 2409-0085 (online)

Year: $2018 \quad$ Issue: 02 Volume: 58

Published: $11.02 .2018 \quad \underline{\text { http://T-Science.org }}$
Gennady Evgenievich Markelov Candidate of Engineering Sciences, associate professor, corresponding member of International Academy of Theoretical and Applied Sciences, Bauman Moscow State Technical University, Moscow, Russia markelov@bmstu.ru

SECTION 2. Applied mathematics. Mathematical modeling.

\title{
MATHEMATICAL MODEL OF A TECHNICAL SYSTEM
}

Abstract: A mathematical model of a technical system was obtained using a unified approach to building a working mathematical model. The technical system consists of a group of serially connected resistors with temperature-dependent resistance and total heat capacity. The constructed mathematical model possesses sufficient fullness, accuracy, adequacy, productivity and economy. Applying such a model reduces the costs and time spent on research and makes efficient use of the mathematical modeling capabilities.

Key words: working mathematical model, properties of mathematical models, principles of mathematical modeling.

Language: English

Citation: Markelov GE (2018) MATHEMATICAL MODEL OF A TECHNICAL SYSTEM. ISJ Theoretical \& Applied Science, 02 (58): 1-4.

Soi: http://s-o-i.org/1.1/TAS-02-58-1 Doi: crossef https://dx.doi.org/10.15863/TAS.2018.02.58.1

\section{Introduction}

Articles [1;2] describe a unified approach to building a working mathematical model that has the desired properties to a degree sufficient for a particular study. Some properties of mathematical models are described in [3; 4]. Article [5] contains an example that describes building a mathematical model that possesses the required properties to a degree sufficient for the study some results of which are presented in [6-8]. The specifics of implementing a unified approach to building mathematical models are discussed in $[9 ; 10]$.
The aim of this study is to build a working mathematical model of a technical system using a unified approach. The technical system consists of a group of serially connected resistors with temperature-dependent resistance and total heat capacity.

\section{Statement of the problem}

Let us consider a group of serially connected resistors shown in Fig. 1. These resistors have temperature-dependent resistance and total heat capacity.

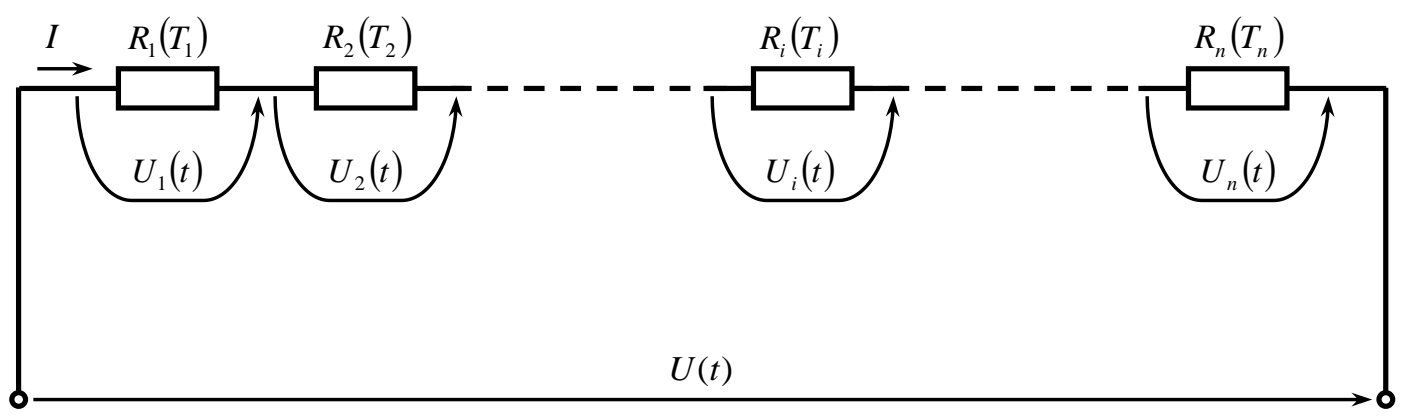

Figure 1 - The group of serially connected resistors.

The $i$ th resistor shall be considered a body with high thermal conductivity, whose temperature $T_{i}$ at the initial time point $t_{0}$ is equal to $T_{i}^{0}$. The resistor has the surface area $S_{i}$ where convective heat exchange with the environment occurs, the ambient 


\begin{tabular}{l|lr|ll|ll} 
& ISRA (India) & $=\mathbf{1 . 3 4 4}$ & SIS (USA) & $=\mathbf{0 . 9 1 2}$ & ICV (Poland) & $=\mathbf{6 . 6 3 0}$ \\
Impact Factor: & ISI (Dubai, UAE) $=\mathbf{0 . 8 2 9}$ & PUH (Russia) $=\mathbf{0 . 2 0 7}$ & PIF (India) & $=\mathbf{1 . 9 4 0}$ \\
& GIF (Australia) & $=\mathbf{0 . 5 6 4}$ & ESJI (KZ) & $=4.102$ & IBI (India) & $\mathbf{4 . 2 6 0}$ \\
& JIF & $=\mathbf{1 . 5 0 0}$ & SJIF (Morocco) & $\mathbf{2 . 0 3 1}$ & & \\
\hline
\end{tabular}

temperature is equal to $T_{i}^{0}$; the heat transfer coefficient is known and equal to $\alpha_{i}$. Let

$$
\begin{gathered}
R_{i}\left(T_{i}\right)=\frac{R_{i}^{0}}{1+\beta_{i}\left(T_{i}-T_{i}^{0}\right)}, \\
C_{i}\left(T_{i}\right)=C_{i}^{0}\left[1+\gamma_{i}\left(T_{i}-T_{i}^{0}\right)\right],
\end{gathered}
$$

where $R_{i}\left(T_{i}\right)$ and $C_{i}\left(T_{i}\right)$ are the resistance and total heat capacity of the $i$ th resistor; $R_{i}^{0}$ and $C_{i}^{0}$ are the resistance and total heat capacity of the $i$ th resistor when $T_{i}=T_{i}^{0} ; \beta$ and $\gamma$ are the temperature coefficients, with $\beta>0$ and $\gamma>0$. The difference of electric potentials at the poles of the $i$ th element is equal to

$$
U_{i}=\frac{U_{i}^{0}}{1+\beta_{i}\left(T_{i}-T_{i}^{0}\right)},
$$

where $U_{i}^{0}=R_{i}^{0} I ; I$ is the direct current flowing through the resistors.

Let us assume that the following value is of interest in this study:

$$
U=\sum_{i=1}^{n} U_{i}
$$

Let us build a working mathematical model of the object of the study which possesses sufficient fullness, accuracy, adequacy, productivity and economy.

\section{Solution}

To solve this problem, we will use the results described in [11]. These results allow us to construct a hierarchy of mathematical models of the object of the study and determine the conditions under which we can calculate the sought value $U$ with a relative error of no more than the specified value $\delta_{0}$.

If the differences $T_{i}-T_{i}^{0}$ and $i=1,2, \ldots, n$ are sufficiently small, then according to (1) the sought value can be calculated using the following formula:

$$
U_{0}=\sum_{i=1}^{n} U_{i}^{0}=\sum_{i=1}^{n} R_{i}^{0} I .
$$

Let us define the conditions under which the resulting formula is applicable. To do this, let us consider steady-state heat transfer. In this case, according to the calculations provided in [11], we can find the steady-state value $U_{i}$ using the following formula:

$$
U_{i}^{*}=\frac{2 U_{i}^{0}}{1+\sqrt{1+4 \beta_{i} I U_{i}^{0} /\left(\alpha_{i} S_{i}\right)}},
$$

then the steady-state value of the sought value is equal to

$$
U_{*}=\sum_{i=1}^{n} U_{i}^{*}=\sum_{i=1}^{n} \frac{2 U_{i}^{0}}{1+\sqrt{1+4 \beta_{i} I U_{i}^{0} /\left(\alpha_{i} S_{i}\right)}} .
$$

$$
\delta\left(U_{0}\right)=\left|\frac{U-U_{0}}{U}\right|=\frac{U_{0}}{U}-1 \leq \frac{U_{0}}{U_{*}}-1 .
$$

Therefore, if the inequality

$$
\frac{U_{0}}{U_{*}}-1 \leq \delta_{0}
$$

is satisfied, we can use formula (3) to find the sought value with a relative error of no more than $\delta_{0}$.

When inequality (5) is satisfied, mathematical model (3) has sufficient fullness, accuracy, adequacy, productivity and economy.

Then let us define the conditions under which mathematical model (4) can be applied. To do this, let us consider an unsteady-state heat transfer. In this case, according to the results from [11], we obtain a Cauchy problem:

$$
\begin{aligned}
& \frac{C_{i}^{0} U_{i}^{0}}{\beta_{i} U_{i}^{2}} \frac{d U_{i}}{d t}=\frac{\alpha_{i} S_{i} U_{i}^{0}-\alpha_{i} S_{i} U_{i}-\beta_{i} I U_{i}^{2}}{\gamma_{i} U_{i}^{0}-\gamma_{i} U_{i}+\beta_{i} U_{i}}, \\
& U_{i}\left(t_{0}\right)=U_{i}^{0},
\end{aligned}
$$

where $i=1,2, \ldots, n$, and we can find the time point

$$
\begin{aligned}
& t_{i}=t_{0}+ \frac{C_{i}^{0}}{\alpha_{i} S_{i}}\left[\frac{\gamma_{i}}{\beta_{i}}\left(\frac{U_{i}^{*}}{U_{i}^{0}}-1+\delta_{0}\right) \frac{U_{i}^{0}}{U_{i}^{*}}+\right. \\
&+\left(\frac{U_{i}^{0}}{2 U_{i}^{0}-U_{i}^{*}}+\frac{\gamma_{i}}{\beta_{i}} \frac{U_{i}^{0}-U_{i}^{*}}{2 U_{i}^{0}-U_{i}^{*}} \frac{U_{i}^{0}}{U_{i}^{*}}-1\right) \times \\
& \quad \times \ln \left(2-\frac{U_{i}^{*}}{U_{i}^{0}}-\delta_{0}\right)- \\
&-\left(\frac{U_{i}^{0}}{2 U_{i}^{0}-U_{i}^{*}}+\frac{\gamma_{i}}{\beta_{i}} \frac{U_{i}^{0}-U_{i}^{*}}{2 U_{i}^{0}-U_{i}^{*}} \frac{U_{i}^{0}}{U_{i}^{*}}\right) \times \\
&\left.\times \ln \left(\frac{U_{i}^{0}}{U_{i}^{0}-U_{i}^{*}} \delta_{0}\right)\right],
\end{aligned}
$$

for which the following is true:

$$
U_{i}\left(t_{i}\right)=U_{i}^{*} /\left(1-\delta_{0}\right) .
$$

For $t \geq t_{i}$

$$
\delta\left(U_{i}^{*}\right)=\left|\frac{U_{i}-U_{i}^{*}}{U_{i}}\right|=1-\frac{U_{i}^{*}}{U_{i}} \leq \delta_{0},
$$

and $U_{i}^{*}$ can be regarded as equal to $U_{i}(t)$ with a relative error of no more than $\delta_{0}$. Let $t_{*}=\max _{1 \leq i \leq n} t_{i}$, then it is easy to demonstrate that for $t \geq t_{*}$

$$
\delta\left(U_{*}\right)=\left|\frac{U-U_{*}}{U}\right|=\sum_{i=1}^{n}\left(U_{i}-U_{i}^{*}\right) / \sum_{i=1}^{n} U_{i} \leq \delta_{0} .
$$

Therefore, formula (4) may be used to find the sought value with a relative error of no more than $\delta_{0}$ when

$$
\delta_{0}<\frac{U_{0}}{U_{*}}-1,
$$

since otherwise formula (3) should be used.

The following is true for the relative error of $U_{0}$ : 


\begin{tabular}{l|lr|ll|ll} 
& ISRA (India) & $=\mathbf{1 . 3 4 4}$ & SIS (USA) & $=\mathbf{0 . 9 1 2}$ & ICV (Poland) & $=\mathbf{6 . 6 3 0}$ \\
Impact Factor: & ISI (Dubai, UAE) $=\mathbf{0 . 8 2 9}$ & PUH (Russia) $=\mathbf{0 . 2 0 7}$ & PIF (India) & $=\mathbf{1 . 9 4 0}$ \\
& GIF (Australia) & $=\mathbf{0 . 5 6 4}$ & ESJI (KZ) & $=4.102$ & IBI (India) & $\mathbf{4 . 2 6 0}$ \\
& JIF & $=\mathbf{1 . 5 0 0}$ & SJIF (Morocco) & $\mathbf{2 . 0 3 1}$ & & \\
\hline
\end{tabular}

If condition (5) is not met, mathematical model (4) possesses sufficient fullness, accuracy, adequacy, productivity and economy when $t \geq t_{*}$.

Building a new mathematical model when creating a hierarchy of mathematical models for the object of the study may lead to refining the previously determined conditions for the applicability of the constructed mathematical models. Indeed, using mathematical model (2), (6), we can refine the applicability condition for formula (3). For this, we need to calculate the time point

$$
\begin{aligned}
& t_{i}=t_{0}+\frac{C_{i}^{0}}{\alpha_{i} S_{i}}\left[\left(\frac{U_{i}^{0}}{2 U_{i}^{0}-U_{i}^{*}}+\right.\right. \\
&\left.+\frac{\gamma_{i}}{\beta_{i}} \frac{U_{i}^{0}-U_{i}^{*}}{2 U_{i}^{0}-U_{i}^{*}} \frac{U_{i}^{0}}{U_{i}^{*}}-1\right) \ln \left(1+\frac{U_{i}^{*}}{U_{i}^{0}} \delta_{0}\right)- \\
&-\frac{\gamma_{i}}{\beta_{i}} \delta_{0}-\left(\frac{U_{i}^{0}}{2 U_{i}^{0}-U_{i}^{*}}+\frac{\gamma_{i}}{\beta_{i}} \frac{U_{i}^{0}-U_{i}^{*}}{2 U_{i}^{0}-U_{i}^{*}} \frac{U_{i}^{0}}{U_{i}^{*}}\right) \times \\
&\left.\quad \times \ln \left(1-\frac{U_{i}^{*}}{U_{i}^{0}-U_{i}^{*}} \delta_{0}\right)\right],
\end{aligned}
$$

for which the following is true:

$$
U_{i}\left(t_{i}\right)=U_{i}^{0} /\left(1+\delta_{0}\right) \text {. }
$$

For $t \leq t_{i}$

$$
\delta\left(U_{i}^{0}\right)=\left|\frac{U_{i}-U_{i}^{0}}{U_{i}}\right|=\frac{U_{i}^{0}}{U_{i}}-1 \leq \delta_{0},
$$

and $U_{i}^{0}$ can be regarded as equal to $U_{i}(t)$ with a relative error of no more than $\delta_{0}$. Let $t^{*}=\min _{1 \leq i \leq n} t_{i}$, then it is easy to demonstrate that for $t \leq t^{*}$

$$
\delta\left(U_{0}\right)=\left|\frac{U-U_{0}}{U}\right|=\sum_{i=1}^{n}\left(U_{i}^{0}-U_{i}\right) / \sum_{i=1}^{n} U_{i} \leq \delta_{0} .
$$

Therefore, formula (3) may be used to find the sought value with a relative error of no more than $\delta_{0}$

If condition (5) is met or $t \leq t^{*}$, mathematical model (3) possesses sufficient fullness, accuracy, adequacy, productivity and economy.

\section{Results}

By constructing a hierarchy of mathematical models of the object of the study, taking into account the results described in [11], we can identify a working mathematical model that has the desired properties to a sufficient degree for a particular study. Indeed, if inequality (5) is satisfied or $t \leq t^{*}$ in the conducted study, then (3) is considered the working mathematical model. If condition (5) is not met, and the time interval from $t_{0}$ to $t_{*}$ may be disregarded in the conducted study, (4) will be chosen as the working mathematical model, otherwise (2), (6) will be the working mathematical model.

\section{Conclusion}

Thus, a unified approach was used to formulate the statements that allow us to define a mathematical model of a technical system. The constructed mathematical model possesses sufficient fullness, accuracy, adequacy, productivity and economy.

It is evident that using such a mathematical model not only reduces the costs and time spent on research, but also makes efficient use of the mathematical modeling capabilities.

\section{References:}

1. Markelov GE (2015) On Approach to Constructing a Working Mathematical Model. ISJ Theoretical \& Applied Science, 04 (24): 287-290.

Soi: http://s-o-i.org/1.1/TAS*04(24)52 Doi: http://dx.doi.org/10.15863/TAS.2015.04.24.52

2. Markelov GE (2015) Constructing a Working Mathematical Model. ISJ Theoretical \& Applied Science, 08 (28): 44-46.

Soi: http://s-o-i.org/1.1/TAS-08-28-6 Doi: http://dx.doi.org/10.15863/TAS.2015.08.28.6
3. Myshkis AD (2011) Elements of the Theory of Mathematical Models [in Russian]. URSS, Moscow.

4. Zarubin VS (2010) Mathematical Modeling in Engineering [in Russian]. Izd-vo MGTU im. N.E. Baumana, Moscow.

5. Markelov GE (2012) Peculiarities of Construction of Mathematical Models. Inzhenernyi zhurnal: nauka i innovatsii, No. 4, Available:

http://engjournal.ru/catalog/mathmodel/hidden/ 150.html (Accessed: 15.02.2018). 


\begin{tabular}{l|lr|ll|ll} 
& ISRA (India) & $=\mathbf{1 . 3 4 4}$ & SIS (USA) & $=\mathbf{0 . 9 1 2}$ & ICV (Poland) & $=\mathbf{6 . 6 3 0}$ \\
Impact Factor: & ISI (Dubai, UAE) $=\mathbf{0 . 8 2 9}$ & PUHЦ (Russia) $=\mathbf{0 . 2 0 7}$ & PIF (India) & $=\mathbf{1 . 9 4 0}$ \\
& GIF (Australia) & $\mathbf{0 . 5 6 4}$ & ESJI (KZ) & $=4.102$ & IBI (India) & $=\mathbf{4 . 2 6 0}$ \\
& JIF & $=\mathbf{1 . 5 0 0}$ & SJIF (Morocco) & $=\mathbf{2 . 0 3 1}$ & & \\
\hline
\end{tabular}

6. Markelov GE (2000) Effect of initial heating of the jet-forming layer of shaped-charge liners on the ultimate elongation of jet elements. J. Appl. Mech. and Tech. Phys., 41, No. 2, pp. 231-234.

7. Markelov GE (2000) Effect of initial heating of shaped charge liners on shaped charge penetration. J. Appl. Mech. and Tech. Phys., 41, No. 5, pp. 788-791.

8. Markelov GE (2000) Influence of heating temperature on the ultimate elongation of shaped-charge jet elements. Proc. of the 5th Int. Conf. "Lavrentyev Readings on Mathematics, Mechanics and Physics", Lavrentyev Institute of Hydrodynamics, Novosibirsk, p. 170.

9. Markelov GE (2015) Particular Aspects of Teaching the Fundamentals of Mathematical
Modeling. ISJ Theoretical \& Applied Science, 05 (25): 69-72.

Soi: http://s-o-i.org/1.1/TAS*05(25)14 Doi: http://dx.doi.org/10.15863/TAS.2015.05.25.14

10. Markelov GE (2016) Teaching the Basics of Mathematical Modeling. Part 2. ISJ Theoretical \& Applied Science, $01 \quad$ (33): $72-74$.

Soi: http://s-o-i.org/1.1/TAS-01-33-15 Doi: http://dx.doi.org/10.15863/TAS.2016.01.33.15

11. Markelov GE (2018) Mathematical Model of a Technical System Element. ISJ Theoretical \& Applied Science, 01 (57): 111-113.

Soi: http://s-o-i.org/1.1/TAS-01-57-20 Doi: https://dx.doi.org/10.15863/TAS.2018.01.57.20 